\title{
CORRELATION OF END TIDAL AND ARTERIAL CARBON DIOXIDE LEVELS IN MECHANICALLY VENTILATED CHILDREN
}

\begin{tabular}{ll}
\hline Pediatrics & \\
$\begin{array}{l}\text { Neeraj Kumar } \\
\text { Sharma }\end{array}$ & MD, Junior Resident, Pediatrics, Indira Gandhi Medical College, Shimla, HP, India \\
\hline $\begin{array}{ll}\text { Parveen } \\
\text { Bhardwaj* }\end{array}$ & MD, Professor, Pediatrics , Indira Gandhi Medical College, Shimla, HP, \\
\hline Minoo Sharma & MD, Associate Professor, Physiology, Indira Gandhi Medical College, Shimla, HP, India \\
\hline Surinder Singh & MD, Associate Professor, Pediatrics, Indira Gandhi Medical College, Shimla, HP, India \\
\hline
\end{tabular}

\section{ABSTRACT}

The study was conducted in paediatric intensive care unit of a tertiary teaching institution of North India from June 2017 to May 2018 to evaluate the relationship between EtCO2 and arterial $\mathrm{PaCO} 2$ in mechanically ventilated children. Study design was prospective observational. All children $(>1$ month and $<18$ years of age) who were intubated and mechanically ventilated were taken in the study. The patients were included in the study after approval of the institutional ethical committee and written informed valid consent obtained from the Guardian of the patient. Total 44 patients were studied. Out of these cases $72 \%$ were males and $22 \%$ were females. The mean age of population was 6.61 years. The overall PaCO 2 was 38.04 $\pm 17.12 \mathrm{mmHg}$ and mean EtCO2 was $33.36 \pm 13.26 \mathrm{~mm} \mathrm{Hg}$. The mean PaCO2 in respiratory and non respiratory group was $43.56 \pm 18.48 \mathrm{~mm} \mathrm{Hg}$ and $33.88 \pm 14.86 \mathrm{~mm} \mathrm{Hg}$ respectively. The mean $\mathrm{EtCO} 2$ in respiratory and non respiratory group was $30.33 \pm 12.21 \mathrm{~mm} \mathrm{Hg}$ and $37.37 \pm 13.66 \mathrm{~mm}$ $\mathrm{Hg}$. The overall correlation coefficient between EtCO2 and $\mathrm{PaCO} 2$ pairs was 0.831 with $\mathrm{P}$ - value of 0.0001 . The correlation coefficient between EtCO2 and $\mathrm{PaCO} 2$ pairs in respiratory group was 0.768 and $\mathrm{P}$ value of $<0.0001$ while in non respiratory group correlation coefficient was 0.848 and $\mathrm{P}$ value was $<0.0001$. in Conclusion a strong positive correlation was observed between $\mathrm{PaCO} 2$ and EtCO2 pairs in our study on mechanically ventilated patients.

\section{KEYWORDS}

\section{Capnography, EtCO2, PaCO2, Correlation, Children}

\section{INTRODUCTION}

Mechanical ventilation is invasive life support undertaken to correct abnormalities in oxygenation $(\mathrm{PaO} 2)$, alveolar ventilation $(\mathrm{PaCO} 2)$ or respiratory effort (Poor, nil or difficult) with multiple effects on the cardiopulmonary system ${ }^{[1]}$. In PICUs and NICUs a number of patients (infants and children) are put on ventilator support for different indications like neurological, cardiorespiratory, metabolic and others (injuries, poisonings, bites) ${ }^{[2]}$. For the monitoring of adequacy of ventilation and oxygenation, only tool that was used in past was ABG which still remains the gold standard to assess the adequacy of cardiopulmonary function. However ABG is expensive, leads to blood loss and iatrogenic anaemia, and each sample is only a snapshot view of the sampling moment. Pulse oximetry provides a non-invasive method of assessing the oxygenation and continuous surveillance of the partial pressure of arterial oxygen $(\mathrm{PaO} 2)^{[1]}$. There is a need for continuous $\mathrm{CO} 2$ monitoring in ventilated patients especially in infants as these patients are more at risk to side effects of hypocarbia and hypercarbia. End-tidal carbon dioxide (EtCO2) monitoring is the non.invasive measurement of exhaled $\mathrm{CO} 2$, first studied clinically by Smallhout and Kalenda in the $1970 \mathrm{~s}^{[3]}$. It has been used extensively in operating theatres and intensive-care units for the past 25 years and increasingly in emergency departments and the prehospital setting ${ }^{[4],[5],[6,[]]}$. The graphic display of $\mathrm{CO} 2$ concentration (or partial pressure) during the respiratory cycle (capnography) has offered many uses in adults $\mathrm{s}^{[8],[9],[10]}$ and pediatric clinical practice ${ }^{[11],[12]}$. EtCO2 reflects metabolism, circulation, and ventilation and is equal to arterial $\mathrm{CO} 2$ if there is no ventilation-perfusion mismatch. The difference is usually 2$5 \mathrm{mmHg}$ lower in $\mathrm{EtCO} 2$ than arterial $\mathrm{CO} 2{ }^{[13]}$. There is limited data about the correlation of EtCO2 and $\mathrm{PaCO} 2$ in mechanically ventilated pediatric patients.

\section{Subjects and Methods:}

This was a prospective observational study. It was carried out in pediatric intensive care unit of tertiary care unit in north India, from June 2017 to may 2018. All patients (between age 1 month and 18 years), who were mechanically ventilated. The exclusion criteria were neonates, children having cyanotic congenital heart disease, significant left to right shunt, severe pulmonary arterial hypertension on ECHO, chronic pulmonary disease, presence of air leak syndrome i.e. pneumothorax ,ventilator circuit leak $\geq 15 \%$, tracheostomized children, intubation for upper airway obstruction., baseline chronic use of invasive or non-invasive respiratory support. This study was carried out after approval by IGMC review board. Written informed consent was obtained from the parent or legal guardian prior to enrolment. Demographical data and clinical data including patient's age and sex, vital signs ( Heart rate, RR, SpO2, CRT/BP ), Input and output charting, Diagnosis, Indication and day of ventilation, ET tube size (cuffed/uncuffed) was abstracted and recorded on Performa. Patients were put on different modes of ventilation on Hamilton Galileo ventilators. Mechanical ventilation settings like mode of ventilation, FiO2, tidal volume (inspiratory and expiratory), PIP, and PEEP were noted. After proper calibration and an equilibration time of minutes with stable hemodynamic and respiratory variables, EtCO2 was recorded using an end-tidal $\mathrm{CO} 2$ analyser (Micro stream ${ }^{\circledR}$ EtCO2

M1920A Filter Line Set H M1921A for adults/paediatric and MP1923A infant/ neonatal, attached to Philips MP70 IntelliVue monitors) attached in between endotracheal tube and ventilator circuit. Highest reading was recorded which was consistent for at least 2 minutes. After recording the EtCO2 levels with the help of capnograph, ABG samples were taken within 5 mins of recording $\mathrm{EtCO} 2$ value. For that, arterial cannulation was done of all the patients included in the study. Blood samples were drawn from arterial line (already secured) and samples were immediately analyzed for $\mathrm{PaCO} 2$ using blood gas analyzer (Cobas b 121 POC systems, Roche Diagnostics Ltd. CH-6343 Rotkreuz Switzerland) in hospital clinical laboratory. A minimum interval of 6 hours was maintained between two successive measurements. SpO2, NIBP, IBP, plethysmography, ECG measurement were recorded on Philips Mp70 Intellivue monitor. PEtCO2 was measured by side stream sampling attached to Philips Mp70 Intellivue monitor. Intermittent $\mathrm{ABG}$ measurement and continuous pulse oximetry $(\mathrm{SpO} 2)$ were carried out. statistical analysis of $\mathrm{EtCO} 2$ and $\mathrm{PaCO} 2$ pair was done by computing $\mathrm{P}$ value, confidence interval, paired t tests, Spearman and Pearson correlation coefficient. Statistical analysis was considered significant if the $\mathrm{P}$ value was $<0.05$.

\section{RESULTS:}

A total of 100 samples $\left(\mathrm{PaCO}_{2}-\mathrm{EtCO} 2\right.$ pairs) were taken from 44 patients satisfying the inclusion and exclusion criteria. On an average 2 samples were withdrawn with range variability of 1-6. Of the total patients, 30 were males and 14 were females. The mean age of the study population was 6.61 years. The most common etiology for ventilation was bronchopneumonia (33\%) followed by Sepsis with ARDS (14\%) in the patients. Others were as depicted in Table 1. 
Indication for ventilation was respiratory distress in $93.59 \%$ patients and respiratory failure (Type $1 \&$ Type 2 ) in $6.41 \%$ of the patients. Xrays were abnormal in $43 \%$ of the $\mathrm{PaCO} 2-\mathrm{EtCO} 2$ pairs. Clinical and ventilator variables were as shown in Table 2

Table 1: Demographic and diagnostic characteristics of infants and children

\begin{tabular}{|l|l|}
\hline Sex & 72 \\
Male & 28 \\
\hline Female & \\
\hline Diagnoses & 33 \\
Respiratory & 14 \\
Pneumonia & 4 \\
ARDS & 7 \\
Croup & 2 \\
Central nervous system & 3 \\
Seizure disorder & 11 \\
Meningitis & 26 \\
Acute febrile encephalopathy & \\
Snake Bite & \\
Others & \\
\hline
\end{tabular}

Table 2 : Clinical and Ventilator variables

\begin{tabular}{|l|l|l|}
\hline \multirow{2}{*}{ Description } & \multicolumn{1}{|c|}{$\mathrm{n}=100$ pairs } & \\
\cline { 2 - 3 } & Mean & $\mathrm{SD}$ \\
\hline Age & 6.61 & 6.61 \\
\hline FiO2 & 55.71 & 18.19 \\
\hline Breaths/min & 28.45 & 7.01 \\
\hline $\mathrm{PIP}$ & 17.98 & 4.61 \\
\hline $\mathrm{PEEP}$ & 6.13 & 1.49 \\
\hline $\mathrm{pH}$ & 7.35 & 0.14 \\
\hline $\mathrm{PaCO} 2$ in $\mathrm{mmHg}$ & 38.04 & 17.12 \\
\hline $\mathrm{PaO}$ in $\mathrm{mmHg}$ & 107.58 & 40.89 \\
\hline $\mathrm{SpO} 2$ & 94.93 & 2.6 \\
\hline \% leak & 5.59 & 3.58 \\
\hline EtCO2 reading & 33.36 & 13.26 \\
\hline
\end{tabular}

Spearman rank correlation coefficient was used to find the correlation of EtCO2 with $\mathrm{PaCO} 2$ as a whole. The mean $\mathrm{PaCO} 2$ was $38.04 \pm 17.12$ $\mathrm{mmHg}$ and mean EtCO2 was $33.36 \pm 13.26 \mathrm{mmHg}$. Total EtCO2 readings were very significantly $\&$ positively correlating with $\mathrm{PaCO} 2$ readings. This is depicted by the correlation coefficient of 0.831 and $p<$ 0.0001(figure: 1 )

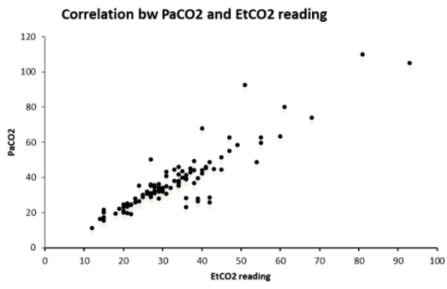

Figure 1 : Correlation between $\mathrm{PaCO} 2$ and EtCO2

The mean $\mathrm{PaCO} 2$ in patients with respiratory and without respiratory illnesses was $43.56 \pm 18.48 \mathrm{mmHg}$ and $33.88 \pm 14.86$ respectively. The mean $\mathrm{EtCO} 2$ in patients with respiratory and without respiratory illnesses was $30.33 \pm 12.21 \mathrm{mmHg}$ and $37.37 \pm 13.66 \mathrm{mmHg}$ respectively. A statistically significant positive correlation existed between $\mathrm{PaCO} 2$ and $\mathrm{EtCO} 2$ pairs drawn from the patients with the respiratory and non-respiratory illnesses. The correlation coefficient and $P$ value in patients with respiratory illnesses were 0.768 and less than 0.0001 whereas in patients with non-respiratory illnesses, the correlation coefficient $\mathrm{r}=0.865$ and $\mathrm{p}<0.0001$ (figure 2 and 3 ). Correlation bw EtCO2 reading and $\mathrm{P}_{2} \mathrm{CO} 2$

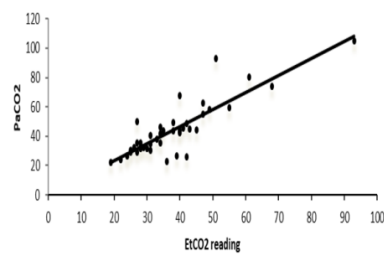

Figure 2. Correlation between $\mathrm{PaCO} 2$ and EtCO2 pairs in patients with Respiratory illnesses
Correlation bw EtCO2 reading and $\mathrm{PaCO} 2$

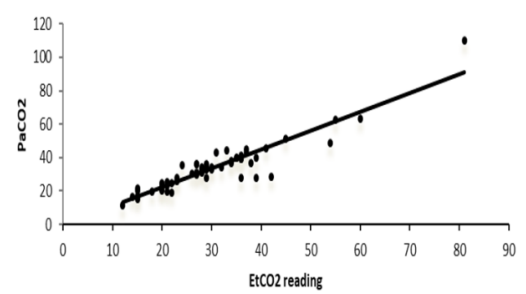

Figure 3. Correlation between $\mathrm{PaCO} 2$ and EtCO2 pairs in patients with non-respiratory illnesses

\section{DISCUSSION:}

In our study $43 \% \mathrm{PaCO} 2$-EtCO2 pairs (total -100 pairs) were taken from patients with respiratory illness. As per the study data, there was significant correlation between $\mathrm{PaCO} 2-\mathrm{EtCO} 2$ pairs $(\mathrm{r}=0.831$, $\mathrm{p}<0.0001)$. Other studies with similar results are depicted in table 3 .

Table 3: Correlation coefficients of $\mathrm{PaCO} 2-\mathrm{EtCO} 2$ pairs in various studies

\begin{tabular}{|l|l|}
\hline Study name & Correlation coefficient (r) \\
\hline Razi et al $^{14}$ & 0.841 \\
\hline${\text { Mehta et } a l^{15}}^{15}$ & 0.836 (neonates) \\
& 0.914 (infants \& children) \\
\hline Garfield et al ${ }^{16}$ & 0.632 \\
\hline Bhat et all & 0.73 \\
\hline Present study & 0.831 \\
\hline
\end{tabular}

It was observed that there was a good and positive correlation in the respiratory group $(\mathrm{r}=0.768, \mathrm{p}<0.0001)$ although it was higher in the non-respiratory subgroup $(\mathrm{r}=0.848, \mathrm{p}<0.0001)$. In the study conducted by Mehta et $\mathrm{al}^{[15]}$, neonates with mild to moderate lung disease, there was a strong correlation of $\mathrm{PaCO} 2-\mathrm{EtCO} 2$ pairs with $\mathrm{r}=0.89(95 \%$ $\mathrm{CI}=0.84-0.92$ ); whereas in severe lung disease, it showed a good correlation of $\mathrm{r}=0.80(95 \% \mathrm{CI}=0.67-0.88)$. In infants and children with mild to moderate lung disease, a significant correlation was observed i.e. $\mathrm{r}=0.94(95 \% \mathrm{CI}=0.91-0.95)$ whereas in severe lung disease the correlation was good $\mathrm{r}=0.782$, but there was a wide $95 \% \mathrm{CI}=0.71$ $0.92 .{ }^{[15]}$ Our study was in accordance with this study. The difference in correlation in a respiratory subgroup can be explained on the basis of ventilation-perfusion mismatch which is higher in this group due to lung pathology. However the P value (0.1539) was insignificant on comparing the coefficient of these subgroups, implying that the difference was not statistically significant. Limitations of the study were that children on higher and low pressure ventilation were not segregated and analyzed separately and number of EtCO2-PaCO 2 pair was less.

To conclude a strong positive correlation was observed between $\mathrm{PaCO} 2$ and $\mathrm{EtCO} 2$ pairs in our study on mechanically ventilated patients. Hence, EtCO2 is a good modality for monitoring arterial carbon dioxide levels in pediatric patients on mechanical ventilation with stable haemodynamics. Moreover, EtCO2 monitoring is cheap, non-invasive and painless, so it should be used in all ICUs with advantage of decrease in repetitive $\mathrm{ABG}$ sampling thereby avoiding unnecessary pricks and pain to patients.

\section{REFERENCES:}

1. Rhein LM. Blood Gas and Pulmonary Function Monitoring. In: Eichenwald EC, Hansen AR, Martin CR, Stark AR, eds. Cloherty and Stark's Manual of Neonatal Care.8th ed. Philadelphia:Lippincott Williams \& Wilkins;2017: 420-6

2. Jadhav J ,Bora B, PokharkarA. Study of etiological factors for ventilatory support in Paediatric age groups in India. International J. of Healthcare and Biomedical Research 2015;03:41-6.

Strauss RG. Transfusion therapy in neonates. AmJ Dis Child 1991; 145.904-11.

4. Sanders A B. Capnometry in emergency medicine. Ann Emerg Med 1989; 18:1287-90.

5. Santos L J, Varon J, Pic.Aluas L, Combs A H. Practical uses of end tidal carbon dioxide monitoring in the emergency department. J Emerg Med 1994; 12:633-44.

6. Helm M, Fischer S. The role of capnography in prehospital ventilation for trauma patients. Int Journal Int Care 2005; 12:124-30.

7. Bhende M S, LaCovey D C. End,tidal carbon dioxide monitoring in the prehospita setting. Prehosp Emerg Care 2001; 5:208-13.

8. McArthur CD, AARC. AARC clinical practice guideline. Capnography/Capnometry during mechanical ventilation - 2003 revision and update. Respir Care. 2003; 48:534-9.

9. Sorenson HM, Shelledy DC, AARC. AARC clinical practice guideline. Intermitten positive pressure breathing - 2003 revision and update. Respir Care. 2003; 48:540-6.

10. Walsh BK, Crotwell DN, Restrepo RD. Capnography/Capnometry during mechanical ventilation: 2011.Respir Care 2011;56:503-9.

11. Eipe N, Doherty DR. A review of pediatric capnography. J Clin Monit Comput. 2010; 24:261-8.

12. Tingay DG, Stewart MJ, Morley CJ. Monitoring of end-tidal carbon dioxide and 
transcutaneous carbon dioxide during neonatal transport. Arch Dis Child Fetal Neonatal Ed. 2005; 90: F523-6.

13. Bhavani.Shanker K, Moseley H, Kumar AY, Delph Y. Capnometry and Anaesthesia. Can JAnaesth1992;39:617-32.

14. Razi E, Moosavi GA, Omidi K, Saebi AK, Razi A. Correlation of End-Tidal Carbon Dioxide with Arterial Carbon Dioxide in Mechanically Ventilated Patients. Arch Trauma Res 2012; 1: 58-62.

15. Mehta H, Kashyap R, Trivedi S. Correlation of end tidal and arterial carbon dioxide levels in critically ill neonates and children. Indian J Crit Care Med 2014; 18:348-53.

16. Fearon DM, Steele DW. End-tidal carbon dioxide predicts the presence and severity of acidosis in children with diabetes. Acad emerg med. 2002; 9:1373-8

17. Bhat YR, Abhishek N. Mainstream end-tidal carbon dioxide monitoring in ventilated neonates. Singapore Med J. 2008; 49:199-203. 